Chandra M. Kumar MBBS FFARCSI DA, Mani Mehta MBBS FRCA

\title{
Ankylosing spondylitis: lateral approach to spinal anaesthesia for lower limb surgery
}

We describe three patients with long-standing ankyolsing spondylitis (AS) who underwent lower limb joint surgery under spinal anaesthesia. At preoperative assessment, it was considered that intubation of the trachea was likely to be difficult or impassible and previous general anaesthesia was associated with increased morbidity. Midline approach spinal anaesthesia failed but the lateral approach was successful. Spinal anaesthesia was induced using a 24 gauge Sprotte (Pajunk) needle with $3.5 \mathrm{ml}$ heavy bupivacaine $0.5 \%$ at the $L_{3-4}$ interspace with the patients in the sitting position. This resulted in adequate sensory blockade for the surgical procedure. None of the patients required airway interventions but equipment and aids to secure airway were available.

Nous décrivons la prise en charge de trois patients souffrant de spondylite ankyolsante avancée soumis à une chirurgie articulaire au membre inférieur sous anesthésie rachidienne. Lévaluation préopératoire laissait entrevoir une intubation difficile ou même impossible. Les suites des anesthésies générales antérieures s'étaient avérées de plus en plus compliquées. L'approche médiane du rachis a échoué, mais la latérale a réussi. L'anesthésie rachidienne a été réalisée avec une aiguille $24 G$ Sprotte (Pajunk) avec $3,5 \mathrm{ml}$ de bupivacaïne hyperbare à $0,5 \%$ en position assise à $L_{3} / L_{4}$. Le bloc sensitif a été suffisant pour lintervention. L'appareillage et l'aide nécessaires pour intervenir sur les voies aériennes étaient prêts en cas de besoin mais n'ont pas été utilisés.

\section{Key words}

ANAESTHETIC TECHNIQUES: spinal; COMPLICATIONS: ankylosing spondylitis.

\footnotetext{
From the South Cleveland Hospital, Middlesbrough, Cleveland TS4 3BW, UK.

Address correspondence to: Dr. Chandra M. Kumar, Consultant Anaesthetist, South Cleveland Hospital, Middlesbrough, Cleveland TS4 3BW, UK.

Accepted for publication 8th September, 1994.
}

Ankylosing spondylitis (AS) is a disease that may deform any portion of the spine and may be encountered in patients who present for corrective surgery of the hips or knees. The uniform development of widespread annular fibrous ossification and the formation of bony bridges (syndesmophytes) are largely responsible for the classic radiographic appearance of the "bamboo spine" of endstage ankylosing spondylitis. ' The closely applied posterior longitudinal ligament and more remote interspinous ligaments may become converted to continuous bony bars, augmenting the spinal rigidity. ${ }^{1}$ These pathological changes can make airway management and mid-line placement of epidural or spinal needles difficult or impossible. ${ }^{2,3}$ Several textbooks of anaesthesia ${ }^{3-5}$ consider that any form of anaesthesia, whether general or more particularly regional, is hazardous despite reports of the successful use of caudal epidural anaesthesia. ${ }^{6}$ The following case reports describe the successful anaesthetic management of lower limb surgery using spinal anaesthesia by the lateral approach in patients with severe ankylosing spondylitis.

\section{Case reports}

\section{Case 1}

A 48-yr-old man weighing $58 \mathrm{~kg}$, height $165 \mathrm{~cm}$ with a 20-yr history of ankylosing spondylitis (AS) was admitted for left knee replacement. He had previously undergone right hip and right knee replacement surgery under general anaesthesia. Tracheal intubation had only been accomplished with marked difficulty on both occasions and had been very distressful to the patient postoperatively. Examination showed that he had a full set of teeth, his chin was touching his chest and the maximal interincisor distance was $2.5 \mathrm{~cm}$. He required seven pillows to support his head due to the disease process and curvature of the cervical spines. History and physical examination suggested that there was severe cervical ankylosing spondylitis involving the thoraco-lumbar vertebral column but without lower limb neurological involvement. Radiographs of the vertebral column revealed ankylosis of cervical, thoracic and lumbar spinous pro- 
cesses showing posterior joint involvement, resorption of the anterior surfaces of the vertebral bodies and calcification and ossification of posterior ligaments and surrounding soft tissues.

It was decided to attempt regional anaesthesia. The insertion of a 19-gauge introducer in the midline for the spinal needle proved to be very difficult. Hence, a lateral approach was tried where the introducer was inserted $1.5 \mathrm{~cm}$ from the midline directly opposite the centre of the interspace between $L_{3-4}$, and the needle was directed slightly upwards towards the lamina of the lower vertebra, and slightly medially. ${ }^{7}$ Spinal anaesthesia was successful at the first attempt with a 24-ga Sprotte spinal needle (Pajunk, Feinwerk, Medizintechnologie, Germany) at the $\mathrm{L}_{3-4}$ interspace in the sitting position and $3.5 \mathrm{ml}$ heavy bupivacaine $0.5 \%$ (Marcain Heavy, Astra Pharmaceuticals Ltd, England) was injected. The patient was then returned to his normal supine position with the required number of pillows. This resulted in a sensory block from $T_{11}$ to the lower sacral segments on both sides. Monitoring included ECG, non-invasive arterial blood pressure and pulse oximetry. Supplementary oxygen was administered continuously during the surgical procedure. There were no intraoperative problems and surgery was performed successfully within two hours. Postoperative analgesia was provided with morphine using patient-controlled analgesia (PCA). There were no postoperative sequelae to the spinal technique.

\section{Case 2}

A 52-yr-old man, weighing $58 \mathrm{~kg}$, height $172 \mathrm{~cm}$ with AS required right hip joint replacement. His chin was touching the anterior chest wall, there was no neck movement, and there was a space between the adjacent teeth in the upper jaw next to the incisors which would have made laryngoscopy and intubation very difficult. He did not suffer from any neurological deficit in the lower limbs. The problems of general anaesthesia with particular reference to difficult intubation were explained to him and he decided to be awake and opted for spinal anaesthesia. An attempt was made to insert the introducer in the midline but this proved impossible. A similar lateral approach technique for the spinal (24-ga Sprotte, Pajunk, Germany), as described above, was successful after few attempts at the level of $\mathrm{L}_{3-4}$ interspace in sitting position using $3.5 \mathrm{ml}$ heavy bupivacaine $0.5 \%$ (Astra Pharmaceuticals Ltd, England) and resulted in a complete sensory and motor block from $T_{10}$ downwards. Standard monitoring included ECG, non-invasive arterial blood pressure and pulse oximetry. Supplementary oxygen was administered during the surgical procedure. The surgical procedure lasted two hours and there were no intraoperative or postoperative problems.
Case 3

A 42-yr-old man weighing $54 \mathrm{~kg}$, height $167 \mathrm{~cm}$ with severe AS spondylitis involving the cervical and thoracolumbar vertebral column had had a left knee replacement surgery under general anaesthesia. Tracheal intubation had proved impossible. The airway had been maintained initially using an oral airway, then with a laryngeal mask airway (LMA \#4 Intavent, Ltd., Berkshire, England). It was noted that frequent adjustment of the head and neck was required to maintain a clear airway during the procedure. Despite receiving prophylactic antibiotic and subcutaneous heparin, he suffered postoperative pneumonia and later developed pulmonary embolism. His condition remained critical for the next two weeks. The patient required exploration of the left knee joint after three weeks because of an increasing haematoma and ruptured wound. The problems of providing general anaesthesia were discussed with the patient and he preferred a regional anaesthetic technique. Midline insertion of an introducer for spinal needle proved impossible but a similar lateral approach technique spinal anaesthesia (24-ga Sprotte, Pajunk, Germany) was performed successfully at the first attempt at the $\mathrm{L}_{3-4}$ interspace in the sitting position using a $3.5 \mathrm{ml}$ heavy bupivacaine $0.5 \%$ (Astra Pharmaceuticals Ltd, England) which resulted in a complete sensory block from $\mathrm{T}_{8}$ downwards. Routine monitoring included ECG, non-invasive arterial blood pressure and pulse oximetry, and the patient received supplementary oxygen during the surgical procedure. The surgical procedure lasted one hour and the intraoperative and postoperative periods were uneventful. The patient subsequently improved and was discharged home with some swelling and pain. Because of the continued problems of pain and swelling, a revision surgery was planned after a few months. Spinal anaesthesia by the lateral approach was again performed and there were no intraoperative and postoperative problems during the period of surgery which lasted two hours. The subsequent postoperative period was uneventful and he was discharged home following a good recovery.

\section{Discussion}

With the increased awareness and interest in the disease, many patients who previously were thought to have mechanical back pain, seronegative rheumatoid arthritis, and other disorders are now recognized as having AS and the true prevalence of AS appears in the region of 0.25 to $1 \%$ with a peak of $2 \%$ in northern Norway. ${ }^{8}$ The aetiology of AS is unknown but numerous bacteria and viruses have been blamed for inducing disease in genetically susceptible individuals. ${ }^{8}$ The diagnosis of AS is made clinically according to accepted criteria. ${ }^{8}$ A small proportion of sufferers develop complete spinal ankylosis 
with or without extra-articular complications. ${ }^{2}$ There is restricted movement of the costovertebral joints, which reduces vital capacity and ventilation becomes progressively dependent on diaphragmatic function. This results in a death rate from respiratory causes 2.5 to 3 times higher than normal. ${ }^{9}$ Stiffness of the cervical spine, atlanto-occipital, temporomandibular and cricoarytenoid joints may cause problems with tracheal intubation. $^{2}$

The identification of a patient at an increased risk of complications, because of problems in the maintenance of the airway, requires discussion with the patient regarding the options for airway management. A patient who is likely to have upper airway problems immediately after loss of consciousness requires an anaesthetic plan in which tracheal intubation is accomplished before anaesthetic induction or immediately after an expeditious induction. ${ }^{10-12}$

It is believed that the patency of airway is surprisingly well maintained despite the loss of bony mobility and most peripheral procedures, for example on the limbs, are carried out without tracheal intubation. ${ }^{5}$ The degree of difficulty in maintaining the airway, either by mask, laryngeal mask airway or by tracheal intubation under direct vision, can range from none to impossible. The difficulty for each technique may be independent, and may change with time. Difficulty in managing the airway is the single most important cause of major anaesthesiarelated morbidity and mortality. ${ }^{\text {" }}$ Whatever technique is selected, the airway must be managed in such a way that it is continuously patent. "Various techniques and algorithms for airway management ${ }^{10,11}$ have been published, but there will still be occasions where anaesthetists are faced with failure to secure the airway, for reasons such as those highlighted above.

Patients with AS may have cardiac and pulmonary disease and therefore are at increased anaesthetic risk. Most anaesthetic-related problems occur because of difficult tracheal intubation. The management of difficult intubation has been simplified as more experience is gained with fibreoptic techniques. ${ }^{13} \mathrm{~A}$ planned and unhurried fibreoptic intubation represents a safe, predictive alternative management strategy for patients with AS. ${ }^{14}$ Concern also exists that if the tracheal intubation has been difficult, the extubation may be hazardous.

Regional anaesthesia is a valuable option if the scope of the surgery is appropriate. It requires the surgery to be defined precisely in duration and site, patient acceptance, easy and accessible anatomy and to incorporate both intraoperative and postoperative analgesia into a single approach. ${ }^{12}$ Use of regional anaesthesia in AS is not new and has been used for appropriate surgery. $2,6,15$ Wittman and Ring ${ }^{16}$ considered epidural or spinal anaesthesia to be contra-indicated in AS because the placement of an epidural or spinal needle may be difficult or impossible due to ossification of interspinous ligaments and bony bridges and tracheal intubation may still be required should there be a complication from the regional technique, such as intravenous injection of local anaesthetic or a very high block.

The choice of spinal anaesthesia in our patients was influenced by the site of surgery, patient preference, the severity of upper airway difficulties and previous anaesthetic problems. There was no cardiovascular or neurological involvement. We were encouraged to use spinal anaesthesia because of a previous report of the successful use of caudal epidural anaesthesia in AS patients for hip surgery. ${ }^{6}$ The cephalad spread of the neural blockade produced by epidural or spinal techniques is a matter of concern because of unpredictable high motor blockade, which may affect innervation of the diaphragm and acute cardiovascular effects of sympathetic blockade. These risks are more likely to occur with epidural anaesthesia rather than with spinal anaesthesia but nevertheless clinically useful dosage guidelines for spinal anaesthesia can provide mid to upper thoracic levels of sensory blockade while still affording a margin of safety for motor

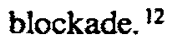

We considered the potential risks of this technique for the patient, which included hypotension, nausea, vomiting, high spinal block, and the failure to achieve adequate block which may have necessitated supplementary anaesthesia. Some of the risks are minor and are handled frequently but they may become important in patients with severe pulmonary or cardiovascular disease. ${ }^{17,18}$ The position of the patients during induction of spinal anaesthesia is known to influence the rate of onset of analgesia and motor blockade and injection $>2 \mathrm{ml}$ heavy bupivacaine $0.5 \%$ has been recommended if induction of spinal anaesthesia is carried out in sitting position. ${ }^{19}$ The higher volume $(3.5 \mathrm{ml})$ of heavy bupivacaine $0.5 \%$ was chosen to compensate for the effect of forced adoption of sitting position, because of pathological process of AS, and to achieve a good conduction block.

The equipment to assist or maintain the airway was immediately available. A difficult intubation cart which had a selection of oropharyngeal airway, nasopharyngeal airway, gum elastic bougie, laryngeal mask airway, fibreoptic laryngoscope, cricothyroidotomy needle, transtracheal-jet-ventilation equipment and other aids including a surgical set for tracheostomy. Anticipated difficulty of access for cricothyroidotomy, surgical tracheostomy and previously assessed difficult airway, choice of regional anaesthesia seemed to have a low risk/benefit ratio.

In our case spinal anaesthesia was established by the lateral approach without difficulty except for failed mid- 
line insertion. Major advantages of the lateral approach are that no flexion of the back is required and there is minimal pain because tough ligaments are avoided, and the sense of touch and needle control are more accurate. ${ }^{20}$ The placement of the spinal needle in the subarachnoid space by the lateral approach was not difficult and the sensation of passage of needle through the ligamentum flavum was no different from that experienced in the mid-line. Although it is generally believed that all the ligaments of the lumbar vertebrae are calcified in AS, a literature search (Computer, CD-Rom, Medline 1990 onward, Cumulated Index Medicus 1980 onwards and various textbooks of Orthopaedic and Rheumatology) failed to show that the ligamentum flavum was involved as often as the interspinous and supraspinous ligaments and our experience confirms that the ligamentum flavum was not affected.

We have shown that spinal anaesthesia by the lateral approach is a feasible and useful technique in AS patients for lower limb surgery. Every plan for anaesthesia in a patient in whom pulmonary ventilation or tracheal intubation may be difficult must include full consideration of airway control even when regional anaesthesia is selected. All necessary precautions should be taken to avoid complications of spinal anaesthesia and facilities to secure airway should be available.

\section{Acknowledgement}

We are very grateful to Dr. Chris Dodds, South Cleveland Hospital, Middlesbrough for critical review of the manuscript.

\section{References}

1 Bluestone R. Arthritis and allied conditions. In: McCarty DJ (Ed.). A Textbook of Rheumatology. Philadelphia: Lee and Febiger, 1979; 610-32.

2 Sinclair JR, Mason RA. Ankylosing spondylitis. The case for awake intubation. Anaesthesia 1984; 39: 3-11.

3 McKenzie PJ, Blogg CE. Orthopaedic and plastic surgery. In: Nimmo WS, Smith G (Eds.). Anaesthesia. Oxford: Blackwell Scientific Publications, 1989; 721.

4 Eisele JH Jr. Connective tissue diseases. In: Katz J, Benumof JL, Kadis LB (Eds.). Anesthesia and Uncommon Diseases, 3rd ed. Philadelphia: W.B. Saunders, 1990; 653.

5 Loach A. Anaesthesia for Orthopaedic Patients. London: Edward Amold, 1983; 28.

6 DeBoard JW, Ghia JN, Guilford WB. Caudal anesthesia in a patient with ankylosing spondylitis for hip surgery. Anesthesiology 1981; 54: 164-6.

7 Lee JA, Atkinson RS, Watt MJ. Sir Robert Macintosh's Lumbar Puncture and Spinal Analgesia: Intradural and Extradural, 5th ed. Edinburgh: Churchill-Livingstone, $1985 ; 164$.
8 Calin A. Ankylosing spondylitis. In: Maddison PJ, Isenberg DA, Woo P, Glass DN (Eds.). Oxford Textbook of Rheumatology, vol 2. Oxford: Oxford University Press, 1993; 671-83.

9 Simmons EH. The surgical correction of flexion deformity of cervical spine in ankylosing spondylitis. Clin Orthop 1972; 86: 132-43.

10 Benumof $J L$. Management of the difficult adult airway: with special emphasis on awake tracheal intubation. Anesthesiology 1991; 75: 1087-110.

11 Benumof $J L$. Management of the difficult airway: the ASA algorithm. Review Course Lecture. Presented at the 67th Congress of the International Anesthesia Research Society San Diego, California March 19-23, 1993: 83-91.

12 Muravchick S. The Anesthetic Plan: From Physiologic Principles to Clinical Strategies. St.Louis: Mosby Year Book, 1991.

13 Hains $J D$, Gibbin KR. Fibreoptic laryngoscopy in ankylosing spondylitis. J Laryngol Otol 1973; 87: 699-703.

14 Hyman SA, Rogers WD, Bullington JC III. Cervical osteotomy and manipulation in ankylosing spondylitis: successful general anesthesia after failed local anesthesia with sedation. J Spinal Disord 1990; 3: 423-6.

15 Simmons $E H$. Kyphotic deformity of the spine in ankylosing spondylitis. Clin Orthop 1977; 128: 65-77.

16 Wittmann $F W$, Ring $P A$. Anaesthesia for hip replacement in ankylosing spondylitis. JR Soc Med 1986; 79; 457-9.

17 Ward RJ, Bonica JJ, Freund FG, Akamatsu T, Danziger $F$, Englesson $S$. Epidural and subarachnoid anesthesia. Cardiovascular and respiratory effects. JAMA 1965;' 191: 275-8.

18 de Jong $R H$. Arterial carbon dioxide and oxygen tension during spinal block. JAMA 1965; 191: 94-8.

19 Patel M, Samsoon G, Swami A, Morgan B. Posture and the spread of hyperbaric bupivacaine in parturients using the combined spinal epidural technique. Can J Anaesth 1993; 40: 943-6.

20 Atkinson RS, Rushman GB, Davies NJH. Lee's Synopsis of Anaesthesia, 1 th ed. London: Butterworth Heinemann 1993; 708. 